|| ISSN(online): 2589-8698 || ISSN(print): 2589-868X || International Journal of Medical and Biomedical Studies

Available Online at www.ijmbs.info

PubMed (National Library of Medicine ID: 101738825)

Index Copernicus Value 2018: 75.71

Volume 3, Issue 4; April: 2019; Page No. 197-200

\title{
STUDY OF EFFECT OF MEDITATION ON GALVANIC SKIN RESPONSE IN HEALTHY INDIVIDUALS
}

\author{
Dr. Reddipogu Pavani ${ }^{1}$, Dr. Akshay Berad ${ }^{2 *}$ \\ ${ }^{1}$ Assistant Professor, Dept. of Physiology, Kurnool Medical College, Kurnool, Andhra Pradesh. India. \\ ${ }^{2 *}$ Associate Professor, Dept. of Physiology, RIMS, Adilabad, Telangana. India.
}

Article Info: Received 11 April 2019; Accepted 25 April. 2019

Cite this article as: Pavani, Dr. R., \& Berad, Dr. A. (2019). STUDY OF EFFECT OF MEDITATION ON GALVANIC SKIN RESPONSE IN HEALTHY INDIVIDUALS. International Journal of Medical and Biomedical Studies, 3(4).

DOI: https://doi.org/10.32553/ijmbs.v3i4.218

Address for Correspondence: Dr. Akshay Berad, Associate Professor, Dept. of Physiology, RIMS, Adilabad, Telangana. India.

Conflict of interest: No conflict of interest.

\section{Abstract}

Meditation practices mainly change functions through autonomous nervous systems, which links brain and body. Meditation is a technique of yoga practiced in India over thousands of years. Long term yogic practices have shown improvement in cardiovascular functions.OM chanting meditation is a concentrative type of meditation involving focusing of attention on breath. The research was conducted with the purpose to study the effect of meditation on galvanic skin response (GSR). 30 healthy individuals in age group 18-20 were selected. The study group is selected based on inclusion and exclusion criteria. GSR recording was taken for period of 3 minutes 3 days such reading were taken and average of these 3 readings was taken as pre test GSR value. Then subjects were instructed about how to do OM meditation for 30 minutes daily for 3 month. Last 3 days of 3 month meditation the GSR values were recorded and considered as post test GSR values. It is seen that GSR value increased after 3 months of regular meditation. This increase was statistically significant $P=0.0419$. There is a significant positive effect of meditation (Om chanting) on galvanic skin response (GSR). GSR can be used as a physiological measure in the study of different emotional and mental states

Key words: Meditation, GSR.

\section{Introduction:}

Meditation is generally an internal, personal practice and done without any external involvement, though many practitioners of meditation may rely on external objects such as candle flames as point on which to focus their attention as an aid to the process. Meditation often involves invoking or cultivating a feeling or internal state, such as compassion, or attending to a specific focal point. Meditation is a mental exercise in which one directs one's mind to think inwardly by shutting one's sense organs to external stimulations. It is a Vedic exercise which can be used as a powerful instrument to restrain sense organs, control autonomic nervous system and also to attain super consciousness. "The word meditation is used to describe practices that self-regulate the body and mind, thereby affecting mental events by engaging a specific attentional set." Meditation practices mainly change body functions through Autonomic nervous system, which links brain and body. It is achieved by excersing the techniques like meditation, yoga, pranayam. Yoga is best lifestyle modification which aims to attain the 
unity of mind body and spirit.(1) Concentrative meditation focuses the attention on the breath. Breath is a dynamic bridge between the body and mind.(2) Galvanic skin response is a type of electrodermal response. A transient change in certain electrical properties of the skin associated with the sweat gland activity and elicited by any stimulus that evokes an arousal or orienting response, known as the galvanic skin response (GSR). It is a change in the electrical properties of a person's skin caused by an interaction between environmental events and the individual's psychological state. GSR is a method of capturing the autonomic nerve response as a parameter of the sweat gland function (i.e., measuring the electrical resistance of the skin). As stress level increases, changes in the electrical resistance of the skin are detected by GSR sensors. GSR varies with its moisture level. So skin conductance is used as an indication of psychological or physiological arousal. Although there are no absolute levels of GSR indicative of high workload or stress, GSR is a good relative indicator of stress. The galvanic skin response (GSR) feedback instrument measures skin conductivity from the fingers and/or palms. The GSR is highly sensitive to emotions in some people. GSR reflects sweat gland activity and changes in the sympathetic nervous system. The activity of the sweat glands in response to sympathetic nervous stimulation (increased sympathetic activation) results in an increase in the level of conductance. Through prayer and meditation a person is expected to get mental peace and this mental peace affects their emotional state. So the present research examines the effect of prayer and meditation (Om chanting) on GSR of students. Om chanting meditation is a concentrative type of meditation that involves focusing of attention on breath and internal or external chanting (or mantra). OM meditation is a concentrative meditation. Studies on OM meditation suggest that mental repetation of OM results in a physiological state at one time characterised by reduced physiological alertness, increased sensitivity, synchronicity as well as changes at specific levels along the auditory pathway suggestive of increased sensitivity to sensory transmission.(3) According to Padma purana the syllable AUM is leader of all prayers A stands for awareness, $U$ for understanding and $M$ for meditation. The word meditation is derived from latin word meditari which means to engage in contemplation or reflection. The present study design aims to find the effect of OM meditation on cardiac and respiratory functions as reflected in heart rate, respiratory rate, blood pressure, and GSR.

\section{Materials and Method:}

30 healthy individuals in age group 18-20 were selected. The study group is selected based on following inclusion and exclusion criteria.

\section{Inclusion criteria:}

- Age $18-20$ years

- Has given written consent.

- Have no acute or chronic illness.

- Are not on any medication at time of study

\section{Exclusion criteria:}

- Individuals with

- Known cardiorespiratory diseases

- Known allergic diathesis

- History of alcohol consumption, cigarette smoking.

- Known psychological disorders

\section{Procedure of the Study:}

GSR: Galvanic skin resistance is recorded using specially designed metal plates placed in contact with volar surface of the distal phalanges of left index and ring fingers provided with polyrite. Prior to reading of the GSR the subjects sat with eyes closed and relaxed for 3-4 minutes. When a normal and relaxed breathing was achieved, GSR recording was taken for period of 3 minutes as this polygraph gives a continuous monitoring of GSR. 3 days such reading were taken and average of these 3 readings was taken as pre test GSR value. 
Then subjects were instructed about how to do OM meditation for 30 minutes daily for 3 months. "First, enter your meditative state by securing a quiet, dimly lit comfortable sitting position. Background meditative music will help facilitate migration into deeper brain centers. Eyes can be open or shut. Breathe comfortably and slowly through your nose, into your belly and then into your chest. Feel that positive energy is running into all over body and each part of your body is pure and holy. Slowly let the air exhale through your mouth. Now chant the mantra, "OM" Visualize a situation when you were very happy and feel that happiness. Feel the positive energy and enjoy in this positive environment". Subjects performed OM meditation daily for 30 minutes for 3 months .Last 3 days of 3 month meditation the GSR values were recorded and considered as post test GSR values. Mean and standard deviation values of pre test and post test were calculated .P value was also calculated.$P$ value $<0.05$ was considered significant.

Results: Table below shows GSR values Pre and Post meditation

Table 1:

\begin{tabular}{|l|l|l|l|}
\hline Parameter & $\begin{array}{c}\text { Pre meditation } \\
\text { Mean } \pm \text { SD }\end{array}$ & $\begin{array}{l}\text { Post Meditation } \\
\text { Mean } \pm \text { SD }\end{array}$ & P Value \\
\hline $\begin{array}{l}\text { GSR } \\
\text { (galvanic skin resistance) }\end{array}$ & $189.63 \pm 86.45$ & $256.51 \pm 85.33$ & 0.0419 \\
\hline
\end{tabular}

It is seen that GSR value increased after 3 months of regular meditation. This increase was statistically significant $P=0.0419$.

The present study revealed a significant increase in GSR values as an effect of meditation which suggested the psychophysiological relaxation. Statistical analysis shows that the meditation significantly affects the GSR values. Increase in GSR values shows the relaxation and decrease in stress level. Findings reveal that the meditation affects the skin resistance of an individual.

\section{Discussion:}

The significant incease in GSR values, after OM meditation practice in present study is in accordance with findings of other studies on physiological effect of meditation practice in healthy individuals.(4) The present study is suggestive of psychophysiological relaxation. In present study a highly significant increase in GSR values can be attributed to modulation of autonomic activity with parasympathetic predominance and relatively reduced sympathetic tone. This autonomic modulation in yoga is mediated through modification of breathing which triggers central and autonomic mechanism and hemodynamic adjustments.( In present study significant reduction in respiratory rate can be explained on basis of altered mental state, reduction in sympathetic activity or inhibition of neural activity. By practicing $\mathrm{OM}$ meditation for few weeks, the bulbopontine complex is adjusted to a new pattern of breathing which is slower than basal rhythm causing decrease in respiratory rate.(5) GSR is a type of electrodermal response. It is a transient change in certain electrical properties of skin associated with sweat gland activity. GSR is a method of capturing the autonomic nerve response as a parameter of sweat gland function.(6) Present study showed marked increase in GSR in individual during $O M$ meditation. It is well established that skin resistance decreases in state of anxiety or stress and increases during relaxation. State of relaxation are accompanied by high skin resistance.(7) Chanting OM mentally causes increased alertness. Diseases like diabetes mellitus type 2, hypertension, asthma, some psychiatric conditions, epilepsy have been assessed by meditation studies and some 
researchers found beneficial effects in patients doing regular OM meditation.(8) shift in balancing components of autonomic nervous system towards parasympathetic state, reduced stress induced sympathetic. Some research shows an elevated Beta endorphin level in person doing regular meditation that may be responsible for relaxed and calm state of regular meditation and also boost immunity.(9)

\section{Conclusion:}

There is a significant positive effect of meditation (Om chanting) on galvanic skin response (GSR). GSR can be used as a physiological measure in the study of different emotional and mental states. It gives a stable and consistent measure of the involvement of the subjects. GSR also indicates the level of concentration during the practice of meditation.

\section{References:}

1. lyenger BKS.7th edition. New Delhi: harpercollins publishers; 2002, Light on yoga.

2. Bijlani R.L.3rd edition. New Delhi: Jaypee brothers;2004. Understanding medical physiology; pp 871-910.
3. Kumar S; Nagendra, H R, Manjunath, $\mathrm{N} \mathrm{K}$ Naveen, and Tellers, S 2010.meditation on OM. Relevance from ancient and contemporary science. International journal of yoga, 3(1),2.5.doi 10.4103/0973-6131. 66771.

4. Bharshankar J R, Bharshankar RN, Deshpande VN. Effect of yoga on CVSin Indian J Physiol.Pharmacol.2003;47:202-6.

5. Doijad V, Surdi A. Effect of short term yoga practice on cardiorespiratory fitness parameters. Int J Basic Med Sci. 2012;3 (5): 38-41.

6. Fuller, GD (1977). Biofeed back methods and procedures in clinical practice. San Fransisco: Biofeedback Press.

7. Johnson L.C \& Lubin A (1966). Spontaneous electrodermal activity during waking \& sleeping. Psychophysiology,3(1),8-17.

8. Davis JL.(2005)meditation balances the body system. Retrieved from www.webmed.com /content/article/99/105340.

9. Harte $\mathrm{JL}$, Eifert $\mathrm{GH}$, Smith R. The effect of running and meditation on Beta endorphin, Corticotropin-releasing hormone and cortisol in plasma and mood. Biol Psychol. 1995 Jun;40(3):251-65. 